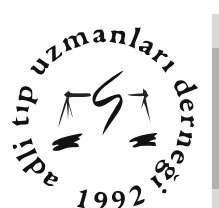

1992

\title{
Antalya İlinde Denetimli Serbestlik Karan Alınan Kişilerde Uyuşturucu Madde Kullanımının Araştırılması
}

\section{Investigation of Narcotic Substance Use among Individuals Who were under Probation in The City of Antalya}

\author{
Burak Kulaksızoğlu ${ }^{1}$, Sibel Kulaksızoğlu ${ }^{2}$, Hamit Yaşar Ellidağ $\breve{g}^{2}$, Necat Yilmaz ${ }^{2}$, Selen Bozkurt ${ }^{3}$
}

${ }^{1}$ Antalya Eğitim ve Araştırma Hastanesi Psikiyatri Bölümü, Antalya

${ }^{2}$ Antalya Ĕ̆itim ve Araştırma Hastanesi Merkez Laboratuvarn, Antalya

${ }^{3}$ Akdeniz Üniversitesi Tıp Fakültesi Hastanesi Biyoistatistik Bölümü, Antalya

\section{Özet}

Amaç: Bu çalışmanın amacı; Antalya Eğitim ve Araştırma Hastanesi Psikiyatri Bölümü'ne denetimli serbestlik kararı alınarak, adli olgu olarak gelen kişilerin madde kullanım özelliklerinin ve sosyodemografik verilerinin retrospektif olarak değerlendirilmesidir.

Materyal ve Metod: 2012-2014 tarihleri arasında Denetimli Serbestlik ve Yardım Merkezi Şube Müdürlüğü’nce (DSYMȘM) hastanemize sevk edilen bireylerin denetimli serbestlik birimi arşivinde kayıtlı dosyaları geriye dönük olarak incelenmiş ve elde edilen veriler hazırlanan veri formlarına kaydedilmiştir.

Bulgular: 2012-2014 yıllarında Antalya Eğitim ve Araştırma Hastanesine denetimli serbestlik kapsamında gelen kişilerde madde kullanımı 2013 yılında \%82, 2014 yılında \%76 oranında artmıştır. Madde kullananların \%97'si erkek olup, esrar kullanım oranı 2013'de \%118 ve 2014 'de ise $\% 102$ oranında artmıştır. Morfin ise sırayla \%43 ve \%42 oranında artmıştır. Kadınlarda madde kullanım sıklığ 2013 yılında $\% 52$ ve 2014 yılında \% 131 oranında artmıştır. Son üç yılda madde kullananların yaş ortalaması düşmüştür. 2014 yılında madde kullananların \%58’i bekar, \% 74’ü ilköğretim mezunu ve \%65’i serbest meslek sahibidir.

Sonuç: Çalışmamızda elde edilen verilere göre Antalya bölgesinde son üç yılda uyuşturucu madde kullanım oranı belirgin düzeyde artmıştır. Madde kullanım oranı diğer illere göre daha yüksek bulunmuştur. En sık kullanılan madde esrardır. Kadınların madde kullanım sıklığı artmıştır. Madde kullanım yaş ortalaması düşmüştür. Madde kullanan kişilerin sadece \% 14'ü tedavi olmak istemiştir.

Anahtar kelimeler: Madde bağımlılı̆̆ı, Denetimli serbestlik, Antalya, Esrar

\section{Giriș}

Kişinin sinir sistemi üzerinde etkide bulunarak akli, fiziki ve psikolojik dengesini bozan, birey ve toplum için ekonomik ve sosyal problemler ortaya çıkaran, alışkanlık ve bağımlılık yapan, kanunların, kullanılmasinı, bulundurulmasinı ve satışının yasaklandığı narkotik maddelere uyuşturucu madde denir. Dünyada olduğu gibi ülkemizde de uyuşturucu madde bağımlılığ

Sorumlu Yazar: Sibel Kulaksızoğlu

Antalya Eğitim ve Araştırma Hastanesi Merkez Laboratuvar, Antalya

E-mail: sblclngrgl@yahoo.co.uk

\section{Abstract}

Objective: The aim of this study is to retrospectively analyze the substance use specifications and sociodemographic data of individuals who were brought to the Clinic of Psychiatry of the Antalya Education and Research Hospital.

Materials and Methods: The recorded files of the individuals in the archives of the probation unit who were referred to our hospital by the Branch Office of the Probation and Help Center (BOPHC) were retrospectively analyzed and the data obtained were recorded in the data form.

Results: When the substance use among the individuals presenting to the Antalya Education and Research Hospital in between 2012 and 2014 were analyzed, substance use had increased $82 \%$ and $76 \%$ between the years 2013 and 2014, respectively. Ninety-seven percent of substance users were male with a $118 \%$ and $102 \%$ increase in marijuana use in 2013 and 2014, respectively. Morphine use increased by $43 \%$ and $42 \%$, respectively. The frequency of substance use in females increased by $52 \%$ and $131 \%$, respectively. The mean age of the substance users has decreased in the last three years. Fifty eight percent of the substance users in the year 2014 were single, $74 \%$ of them graduated from the secondary school, and 65\% were self-employed.

Conclusion: Narcotic substance use increased markedly in the last three years in the Antalya region, according to the data obtained in this study. The rate of substance use was higher when compared to the other cities. The most commonly used substance was marijuana. Substance use increased among women. The mean age of the substance users decrease. Only $14 \%$ of the substance users desired to be treated.

Keywords: Drug addiction, Probation, Antalya, Cannabis

biyolojik boyutları olan bir toplumsal sorundur (1).

Uyuşturucu maddeler eroin, esrar, kokain gibi reçeteyle verilmeyen yasadışı maddeler olabileceği gibi, benzodiazepinler, amfetaminler, diğer sedatif hipnotik ilaçlar ve sentetik uyuşturucu maddeler gibi yasal düzenlemeler çerçevesinde reçeteyle verilebilen ilaçlar ya da yasal denetimlere tabi olmayan veya satışlarında kısmi yasal düzenlemeler olan uyuşturucu maddeler olabilir. Dünyanın pek çok ülkesinde olduğu gibi ülkemizde de uyuşturucu maddeler arasında en yaygın kullanılanın esrar olduğu belirtilmektedir. Madde kullanıcılarında esrar kullanımının yanı sira sigara, alkol, morfin, eroin ile sentetiklerden bonzai, 
kaptagon, ekstazi gibi maddelerin kullanımı da yaygın olarak görülmektedir. Bonzai, ekstazi, amfetamin ve metamfetamin gibi yeni tür sentetik ilaçların kullanımı ülkemiz gibi gelişmekte olan ülkelerde giderek yaygınlaşmaktadır $(1,2,3)$.

Özellikle son on yılda uyuşturucu maddelerin kullanımı hızla artmıştır. Bu nedenle madde kullanımının getirdiği sorunlar dikkate alınmalı ve önemsenmelidir. Madde kullanımı; cinsiyet, aile, kişilik, sosyoekonomik durum, alkol, sigara, arkadaş-okul çevresi ve yaş faktörleri ile oldukça yakından ilişkilidir. Çalışmalara göre uyuşturucu madde kullanımının özellikle genç nüfusta ve liman ya da limana yakın şehirlerde yüksek oranda olduğu saptanmıştır $(1,2,3)$.

Madde kullanımının yaygın olduğu ülkeler, yasal önlemler almak zorunda kalmıştır $(4,5)$. Ceza kavramı ve uyuşturucu madde bağımlılarının rehabilitasyonu konusunda önemli bir adım olarak başlatılan denetimli serbestlik sistemi ülkemizde, 01 Haziran 2005 tarihinde yürürlüğe girmiştir. Denetimli serbestlik uygulamaları uyuşturucu madde bağımlılı̆ının tedavisinde oldukça etkili bir sistemdir. Resmî Gazete'nin 20.07. 2005 tarihli ve 25881 sayısında yayımlanarak yürürlüğe giren denetimli serbestlik, ülkemizde cezai yaptırım ve güvenlik tedbirleri açısından da önemli bir uygulamadır. 5237 sayılı Türk Ceza Kanunu'nun 191. maddesi ve 5271 sayılı Ceza Muhakemesi Kanunu'nun 109. maddesi kapsamındaki kişilerin; "Denetimli Serbestlik bürolarınca düzenlenmiş sevk belgeleri ile birlikte bünyesinde ruh sağllğı ve hastalıkları uzmanı görev yapan ve laboratuvar imkânları yönüyle desteklenmiş devlet hastanelerine yönlendirilmeleri" ve "Bu hastanelerde ilk muayene ve takiplerinin yapılarak laboratuvar ve klinik bulgulara göre bağımlı olduklarına karar verilen kişilerin ruh sağlığı ve hastalıkları uzmanınca belirtilen madde bağımlllığ tedavi merkezlerine sevk edilmeleri” uygundur, şeklinde öngörülmektedir. Uyuşturucu madde kullanma suçu ile yakalanıp mahkeme tarafindan denetimli serbestlik kararı verilen kişi sayısı giderek artmaktadır. 2010 yılında denetimli serbestlik kararı verilen kişi sayısının 49465 olduğu bildirilmektedir. Narkotik Şube Müdürlügü̉nün verilerine göre en fazla uyuşturucu madde kullanılan iller sırasıyla İstanbul, Bursa ve İzmir; ardından da Antalya gelmektedir. Antalya ilinde denetimli serbestlik verileri ile ilgili kapsamlı bir çalışma bulunmamaktadır $(2,3,6)$

2006 yılından beri ülkemizde denetimli serbestlik hizmetleri uygulanmasına rağmen bu konuda literatür bilgileri kısıtlıdır. Ülkemizdeki tıbbi kayıt sisteminin yetersizliğinden dolayı madde kullanımının geçmiş yıllardaki yaygınlığı tam olarak bilinmemektedir. Bu çalışmanın amacı; denetimli serbestlik kararı alınarak, Antalya Eğitim ve Araştırma Hastanesi Psikiyatri Bölümü'ne adli olgu olarak gelen kişilerin madde kullanımı ve sosyodemografik özelliklerinin incelenerek Antalya ilinde uyuşturucu madde kullanım yaygınlığı hakkında veri elde etmek, gereksinimleri belirlemek ve ileri araştırmalar planlamaktır.

\section{Gereç ve Yöntem}

Çalışmada 1 Ocak 2012-31 Aralık 2014) tarihleri arasında denetimli serbestlik kararı alınarak Antalya Eğitim ve Araştırma Hastanesi Psikiyatri Bölümü'ne adli olgu olarak gelen kişilerin madde kullanım özellikleri dosyalarından retrospektif olarak incelendi. Bu kişilerin sosyodemografik verileri rutin uygulamada kişiler tarafından doldurulmaktadır. Bu çalışmada sadece 1 Ocak-31 Aralık 2014 tarihleri arasında denetimli serbestlik kararı ile gelen olguların sosyodemografik verileri retrospektif olarak değerlendirildi.

Denetimli serbestlik kararı ile psikiyatri polikliniğine gelen kişiler öncelikle iki hafta arayla üç kez idrar analizleri için idrar örnekleri verirler. Üç testi de negatif ise takipleri denetimli serbestlik müdürlügü tarafından yapılır. İki hafta arayla yapılan üç idrar testinin en az birinde pozitiflik tespit edilirse, bireyin madde kullanımının devam ettiği düşünülür ve psikiyatrist tarafından 6 haftalık ayaktan denetimli serbestlik madde bağımlılığı eğitim programına alınır, bu süre içerisinde bireyin idrarında uyuşturucu maddenin negatif saptanması durumunda aynı şekilde takibinin denetimli serbestlik ve yardım merkezi şube müdürlüğü (DSYMŞM) tarafından sürdürülmesi gerektiği bildirilmektedir. Ancak bireyin 6 haftalık eğitim programına uyum gösterememesi, idrarda uyuşturucu maddenin pozitif bulunması, yoksunluk tablosu veya intihar riski bulunan durumlarda en yakın alkol ve madde bağımlılığı tedavi merkezi (AMATEM)'ne sevkinin sağlanması yönünde DSYMŞM'ne rapor edilmektedir (6). Bu uygulama Psikiyatri adli vaka polikliniğinde rutin olarak yapılmaktadır. Çalışmaya özel ek bir müdahale yapılmamıştır. Bu veriler geriye yönelik incelenmiştir.

Antalya Denetimli Serbestlik Müdürlügüu’nden adli olgu olarak gönderilen bireyler, psikiyatri uzmanları tarafindan psikiyatrik açıdan değerlendirilip, DSM-IV tanı ölçütlerine göre madde bağımlilığ 1 değerlendirilmekte ve bilgi formu doldurulmaktadır (6). Sonrasında bireylerden idrar örneği alınarak biyokimya laboratuvarında "instant- view multi-drug of abuse urine test kiti” ile manuel olarak idrarda uyuşturucu madde analizi yapılmaktadır. Laboratuvarımızda idrarda amfetamin, barbitürat, benzodiazepin, kokain, fensiklidin, metamfetamin, morfin, tetrahidrakanabinol ve trisiklik antidepresanlar gibi yoğun olarak kullanılan uyuşturucu ve uyarıcı madde analizlerinde immünokromatografik yöntem kullanılmaktadır.

Veriler PASW SPSS 18 programı kullanılarak analiz edildi. Örneklemi tanımlamak için frekans dağılımı, ortalama, 
standart sapma gibi tanımlayıcı istatistikler kullanıldı. Parametrik test varsayımlarının sağlandığ $\breve{1}_{1}$ durumlarda bağımsız iki grup ortalamalarının farkı "Student $t$ testi”, ikiden fazla grup arası fark ise "varyans analizi" ile araştırıldı. Parametrik test varsayımlarının sağlanmadığı durumlarda ise bu testlerin parametrik olmayan alternatifleri, "Mann-Whitney U” ve "Kruskall Wallis" testleri kullanıldı. Analizlerde farkllıkların belirlenmesi için \% 95 anlamllık düzeyi (ya da $\alpha=0.05$ hata payı) kullanıldı.

\section{Bulgular}

2012, 2013 ve 2014 yıllarında Antalya Eğitim ve Araştırma Hastanesi'ne denetimli serbestlik kapsamında gelen kişilerin demografik verileri Tablo 1'de verilmektedir. Antalya ilinde madde kullanımı, 2012 yılına göre; 2013 yılında \% 82, 2014 yılında ise \%76 oranında artmıştır (Tablo 1). Tam idrar testinde "pozitif” bulunan maddelerin yıllara göre dağılımı Tablo 2 ve Grafik 1'deki gibidir.

Tablo 1. 2012, 2013 ve 2014 yılları arasında Antalya Eğitim ve Araştırma Hastanesine denetimli serbestlik kararı ile adli olgu olarak gelen kişilerin sayı, cinsiyet ve yaş ortalaması.

\begin{tabular}{|l|c|c|c|}
\hline Özellikler & $\mathbf{2 0 1 2}$ & $\mathbf{2 0 1 3}$ & $\mathbf{2 0 1 4}$ \\
\hline Kişi Sayısı & 1359 & 1386 & 1302 \\
Erkek/Kadın & $1309 / 50$ & $1268 / 118$ & $1233 / 69$ \\
Yaş Ort & $27,35 \pm 8.88$ & $29,25 \pm 11.41$ & $27,08 \pm 8.68$ \\
\hline
\end{tabular}

Tablo 2. İdrar testinde pozitif olan maddelerin yıllara göre dağılımı.

\begin{tabular}{|l|c|c|c|}
\hline Özellikler & $\mathbf{2 0 1 2}$ & $\mathbf{2 0 1 3}$ & $\mathbf{2 0 1 4}$ \\
\hline Amfetamin & 12 & 3 & 4 \\
Barbitürat & 0 & 0 & 0 \\
Benzodiazepin & 26 & 39 & 37 \\
Kokain & 24 & 42 & 47 \\
Fensiklidin & 12 & 44 & 35 \\
Metamfetamin & 4 & 12 & 9 \\
Morfin & 100 & 143 & 142 \\
Esrar (THK) & 156 & 341 & 316 \\
TAD & 20 & 21 & 33 \\
\hline TOTAL & 354 & 645 & 623 \\
\hline
\end{tabular}

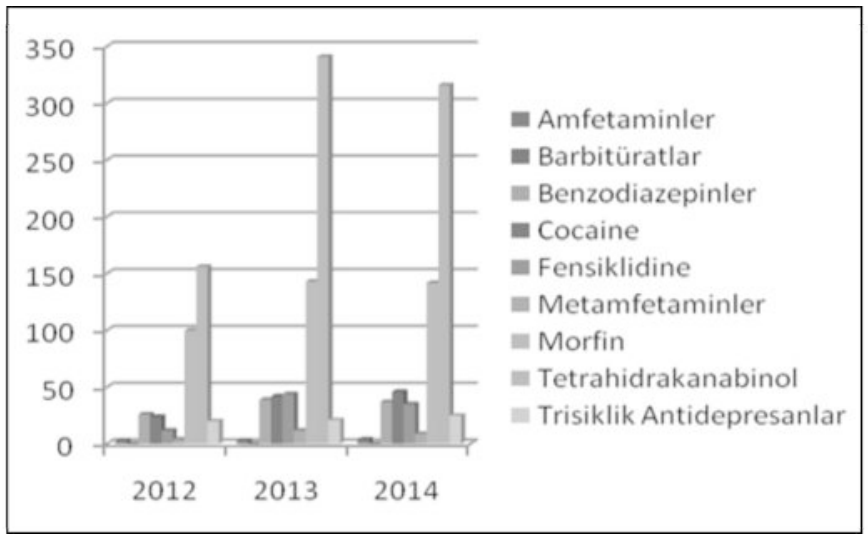

Grafik 1. Yıllara göre kişilerin uyuşturucu madde kullanım sıklığı.

Esrar kullanımı 2012 yılına göre 2013'de \%118ve 2014'de ise \%102 oranında artmıştır. Bununla birlikte 2013 yılına göre 2014'de \%3.4'lük bir azalış vardır. Morfin kullanım oranı ise \%43 ve \%42 oranında artmıştır (Grafik 1).

2014 yilında madde kullanan 87 kişinin (\%14) tedavi olmak istemesi üzerine AMATEM'e sevkinin sağlanması yönünde DSYMŞM'ye rapor edilmiştir. Kadınlarda barbitüratlar ve amfetamin pozitifliğine rastlanmamıştır. Kadınlarda 2012'ye göre 2013 ve 2014 yıllarında madde kullanım sıklığı artmıştır (\%52,\% 131). Son üç yılda kadınlarda özellikle benzodiazepinler ve trisiklik antidepresanların kullanımı istatistiksel olarak anlamlı düzeyde artmıştır ( $\mathrm{p}<0.05$, Tablo 3$)$.

Tablo 3. Kadınlarda uyuşturucu madde kullanımı.

\begin{tabular}{|l|c|c|c|}
\hline Ozellikler & $\mathbf{2 0 1 2}$ & $\mathbf{2 0 1 3}$ & $\mathbf{2 0 1 4}$ \\
\hline Amfetamin & 0 & 0 & 0 \\
Barbitürat & 0 & 0 & 0 \\
Benzodiazepin & 3 & 6 & 8 \\
Kokain & 2 & 2 & 5 \\
Fensiklidin & 1 & 4 & 4 \\
Metamfetamin & 0 & 0 & 1 \\
Morfin & 4 & 9 & 9 \\
Esrar (THK) & 8 & 1 & 5 \\
\hline TAD & 1 & 29 & 44 \\
\hline TOTAL & 19 & & \\
\hline
\end{tabular}

Yıllara göre uyuşturucu madde kullanım yaşı giderek düşmüştür. Özellikle 2013 ve 2014 yıllarında morfin kullanan kişilerin yaş ortalaması istatistiksel olarak anlamlı düzeyde düşük bulunmuştur ( $<<0.01$,Grafik 2). 
2014 yılında madde kullananların \% 58'inin bekar, \% 74'ünün ilköğretim mezunu ve \% 65’inin serbest meslek sahibi olduğu gözlenmiştir.

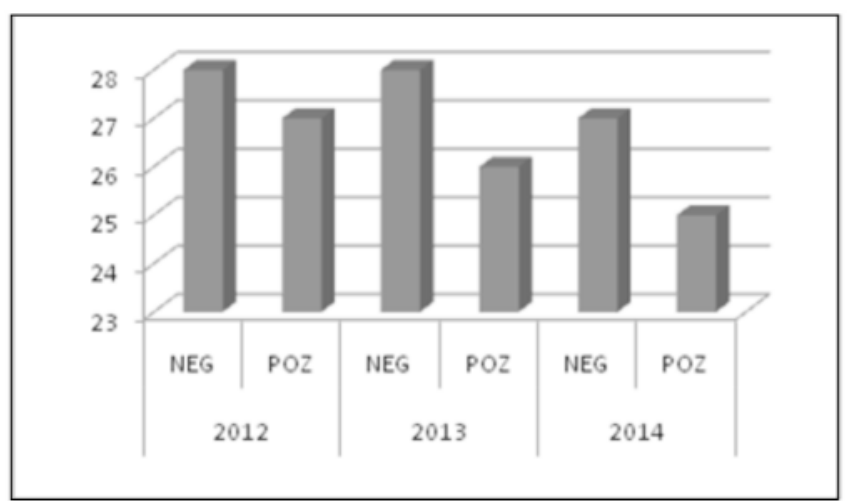

Grafik 2. Yıllara göre uyuşturucu madde kullanımının yaşa göre değerlendirilmesi.

\section{Tartışma}

1 Ocak 2012-31 Aralık 2014 tarihleri arasında Antalya Eğitim ve Araştırma Hastanesi Psikiyatri polikliniğine denetimli serbestlik kararı ile gelen kişi sayısı 2012, 2013 ve 2014'de sirayla; 1359, 1386 ve 1302'dir. Bu kişilerden 2012'de 354, 2013'de 645 ve 2014'de 623'ünün idrar örneklerinde madde pozitif bulunmuştur. 2012 yılına kıyasla 2013 ve 2014 yıllarında madde kullanım oranı \% 82 ve \% 76 oranında artmıştır. Literatürde, Rize'de bir Eğitim ve Araştırma Hastanesine denetimli serbestlik kapsamında başvuran kişiler 2011 yılı için değerlendirilmiş ve 201 kişi olduğu, yine 2010 yılı içinde Ege Üniversitesi Psikiyatri bağımlılık tedavi birimine denetimli serbestlik kapsamında başvuran kişi sayısının 129 olduğu gözlenmiştir $(6,7)$. Bu verilere göre bize başvuran denetimli serbestlik adli olgu sayısı, Rize'deki verilerle karşılaştırıldığında her üç yılda da yaklaşık 6.7 kat, İzmir'deki verilere göre ise 10.5 kat daha fazla olduğu görülmektedir. Bunun nedeni olarak Antalya ilinde tüm denetimli serbestlik olgularının Antalya Eğitim ve Araştırma Hastanesi'ne yönlendirilmesi, ayrıca turistik, limanı olan bir şehir olması veya tutulan kayıtlardaki yetersizlik gösterilebilir.

İdrarda toksikolojik madde testinin adli ve klinik amaçlı kullanımı oldukça yaygındır. Klinik toksikolojik testlerde doğruluk kadar hız da önemlidir, alınacak sonuca göre tedaviye başlanacaktır. Adli amaçlı yapılan bir toksikolojik analizde ise en önemli etken, sonucun geç de olsa kesin doğruluğudur. Mevcut bir maddenin kişide saptanamaması veya kullanılmayan bir maddenin bulunması gibi durumların oluşmaması için toksikolojik analizlerde uygun tarama yöntemleri kullanılmalıdır. Sonuçların daha hassas ve uluslararası standartlara uygun yöntemlerle doğrulanması gerekmektedir. Adli toksikolojik analizleri yapan laboratuvarların; personel, örnek toplama, güvenlik, analitik prosedürler, kalite kontrol, veri değerlendirme, raporlandırma gibi tüm aşamalarının belirli bir standartta olması gerekmektedir. Laboratuvarımızda idrarda amfetamin, barbitürat, benzodiazepin, kokain, fensiklidin, metamfetamin, morfin, tetrahidrakanabinol ve trisiklik antidepresanlar gibi sık kullanılan uyuşturucu ve uyarıcı madde analizlerinde; immünokromatografik yöntem ile çalışılmaktadır. (6).

2005'de Birleşmiş Milletler Madde Kullanım Programı verilerine göre dünyanın \% 4'ünün esrar kullandığı saptanmıştır $(8,9,10)$. Ülkemizde de TUBİ (Türkiye Uyuşturucu Ve Uyuşturucu Bağımlılı̆̆ İzleme Merkezi) 2013 verilerine göre Genel Nüfusta Madde Kullanım Araştırması'nda esrar [tetrahidrakanabinol]; en çok kullanılan uyuşturucu madde olarak belirlenmiştir. Araştırmaya katılanların \% 0,7'si, esrarı yaşam boyu en az bir kez kullandıklarını ifade etmişlerdir (2). 2011 yıllında Rize'de yapılan araştırmaya göre madde kullananlar arasında esrar kullanma sıklığının \%97.5 olduğu gözlenmiştir (6). 2008'de Baltimore'de yapılan çalışmada 94 madde bağımlısı kişide \%77 morfin, \%15 opiat ve \%8 kokain ve diğer maddeler kullanılırken, yine 2008'de California'da 1459 madde bağımlısında \%52.6 metamfetamin, \%13.5 esrar \%22 diğer maddeler kullanıldı̆̆ı gözlenmiştir $(12,13)$. Bizim bulgularımıza göre özellikle 2013 ve 2014 yıllarında tetrahidrakanabinol (esrar) ve morfin kullanımındaki artış istatistiksel olarak anlamlı bulunmuştur. $(\mathrm{p}<0.05)$. Esrar kullanımı 2012 yılına kıyasla 2013'de \%118 ve 2014'de ise \%102 oranında artmıştır. Morfin ise \%43 ve \%42 oranında artmıştır. Bulgular esrarın alkol ve sigaradan sonra en sik kullanilan psikoaktif madde olduğunu desteklemektedir. Esrarın en çok tercih edilme sebebi ucuz olması, daha kolay bulunması ve bağımlılık yapmaz gibi yanlış bir kanının olmasından kaynaklanmaktadır.

Türkiye ve dünyada özellikle genç nüfusta madde kullanımının arttığ bilinmektedir (14). TUBIM 2013 verilerine göre esrarın ilk kez kullanılma yaşı ortalaması $20,89 \pm 3,99$ ve en fazla esrar kullanıcısının bulunduğu yaş aralığının 15-24 yaş arası olduğu belirtilmektedir (2). Esrar dahil herhangi bir uyuşturucu maddeyi yaşamında en az bir kez kullananlar 15-64 yaş grubunda \% 2,7, 15-16 yaş grubunda ise \%1,5 olarak belirlenmiştir (2.3). Madde kullanımıyla ilgili olarak yapılan çalışmalarda yaş ortalaması Baltimore'de 16.9 (12), California'da 34.9 (13) olarak bildirilmektedir. Bu konuda ülkemizde 2011 yılında Rize'de madde kullanım yaş ortalaması 33.7 iken, 2010 yılında İzmir'deki çalışmaya göre yaş ortalaması 33.1, 2008'de Trabzon'daki çalışmada ise 32.47 bulunmuştur $(6,7,15)$. Bizim verilerimizde de yıllara göre uyuşturucu madde kullanım yaşı giderek düşmüştür. Özellikle 2013 ve 2014 yıllarında morfin kullanan kişilerin yaş ortalaması istatistiksel 
olarak anlamlı düzeyde düşük bulunmuştur $(\mathrm{p}<0.01)$ Son üç yılda madde kullananların yaş ortalaması 27'den 25'e düşmüştür. Toplumlar arası madde kullanımında yaş farkı nedeni olarak, sosyoekonomik farklılıklar, çalışmaların belli yaş grubunu kapsaması ya da madde ile karşılaşma yaşındaki farklar gösterilebilir. Genç toplumda madde kullanım oranının giderek arttığı görülmektedir. Bunun nedenleri arasında ailesel sorunlar, arkadaş etkisi, zayıf sosyoekonomik durum ve özenti gibi faktörler gösterilebilir. Bu tür çalışmalar, madde kullanan kişilerin sosyodemografik verilerinin değerlendirilip alınması gereken önlemler açısından önem taşımaktadır. Gençler uyuşturucu madde konusunda bilgilendirilmelidir.

2013 TUBİM verilerine göre erkeklerde yaşam boyu uyuşturucu madde kullanımı \%3,5 bulunmuşken kadınlarda \%2,6'dır ve uyuşturucu madde kullananların çoğunluğunu erkek cinsiyeti oluşturmaktadır (2). Bizim verilerimize göre denetimli serbestlik kararı ile hastanemize gelen kişilerin her üç yılda ortalama \%96'sı erkek, \% 4'ü kadın olup, kadınlarda 2012'de \% 38, 2013'de \%24, ve 2014'de \% 63'ünde madde kullanımı pozitif bulunmuştur. Madde kullanan kişilerin çoğunluğunun erkek olması literatürle uyumludur $(6,7)$. Kadınlarda 2012'ye göre madde kullanım siklı̆̆ yıllara göre sırayla 1.5 ve 2.3 kat artmıştır. Bu da son yıllarda kadınlarda madde kullanımının arttığını göstermektedir. Kadınlarda barbitüratlar ve amfetamin pozitifliğine rastlanmamıştır. Son üç yılda kadınlarda özellikle benzodiazepinler ve trisiklik antidepresanların kullanımı istatistiksel olarak anlamlı düzeyde artmıştır. $(\mathrm{p}<0.05)$. Kadınlarda madde kullanımında görülen bu artış, madde kullanımının arkadaş ortamı veya eş etkisi ile ortak mekanlarda paylaşımı ya da madde teminindeki kolaylıklar şeklinde yorumlanabilir.

Türkiye'de madde bağımlılı tedavisi AMATEM'lerde, üniversitelerin tıp fakültesi psikiyatri kliniklerinde, Sağlık Bakanlığı devlet hastanelerinde ve bazı özel hastanelerin ilgili birimlerinde yapılmaktadır. TUBIM verilerine göre yatarak tedavi gören hastaların sayısı, 2011 yılında 2.117 iken, 2012 yılında yaklaşı \% 123 'lük bir artışla 4.720 olduğu görülmektedir (2). Çalışmamızda 2014 yılında ilk başvuruda testleri pozitif çıkan 87 (\%14) kişi tedavi olmak istemiş ve bu kişiler denetimli serbestlik kapsamında tedavi amaçl AMATEM merkezlerine yönlendirilmiştir. Baltimore'da yapılan çalışmada madde kullananların \%39.8'unun, California'da \%35.7'sinin, İzmir'de \%46.5’nin tedavi edildiği bildirilmektedir $(7,12,13)$. Bizim çalışmamızda ise AMATEM merkezi hastane bünyesinde olmadığ 1 için tedavi sonucu hakkında verilerimiz bulunmamaktadır. Fakat çalışma genişletilerek madde kullananların akıbetlerine yönelik veri tabanları oluşturulabilir kanaatindeyiz.

Ülkemizde 2011 yılında TUBIM tarafından ilk kez yapılan araştırmada elde edilen bilgiler sonucunda denetimli serbestlik hizmetlerine alınan bireylerin çoğunlukla ilköğretim mezunu ve bekar olduğu saptanmıştır $(2,3)$. Yapılan çalışmalarda madde kullananlar arasında Trabzon'da \%56.7, İzmir'de \%89, Rize'de \% 64.1'nin ilköğretim mezunu, olduğu bildirilmektedir $(6,7,15)$. Bizim bulgularımıza göre de madde kullananların eğitim düzeyi düşük bulunmuştur. Çalışmamızda 2014 yılında madde kullananların, \% 74'ü ilköğretim mezunu olduğu görülmektedir. Elde edilen bilgiler, madde kullanım sürecinde eğitim düzeyinin ne kadar önemli olduğunu göstermektedir $(6,7,12,16)$. Madde bağımlılığı ile mücadelede özellikle eğitimcilerin ilköğretimden başlayarak madde kullanımının zararları hakkında bilgi verilmesi ve eğitime gereken önemin verilmesi oldukça önemlidir. Ayrıca çalışmamızda sosyodemografik veriler 2014 yılı ile sınırlı kalmıştır. Verilerin kayıt altında tutulması madde bağımlılığı ile mücadelede oldukça önemlidir.

Literatürle uyumlu bir diğer bulgumuz, madde kullanan kişilerin \%58'nin bekar ve \%65’i serbest meslek sahibi olmasıdır $(6,16)$. Bu veriler aile kurmanın, düzenli bir aile hayatının maddeyle mücadelede önemini göstermektedir. İşsizlik düzeylerinin beklenenden düşük çıkması, dosyaların kişiler tarafından doldurulması ve işsiz olan kişilerin serbest meslek sahibi şeklinde bilgi vermelerinden kaynaklanabileceğini düşünmekteyiz. 2010'da Rize'de yapılan çalışmada madde kullananların \%58.7'si işsiz, Trabzon'da \%47.2'si esnaf ve \%10'u işsiz olarak bildirilmektedir $(6,15)$. İşsizlik madde kullanımını etkileyen bir faktör olarak önemsenmeli ve meslek kazandırmanın olanakları için çalışmalarda bulunulmalıdır.

\section{Sonuç}

Antalya'da son yıllarda uyuşturucu kullanımı artmıştır. Uyuşturucu kullanımının sosyal ve psikolojik etkileri düşünüldüğü zaman gerek bireysel gerek toplumsal etkileri büyüktür. Bu konuda elde edilen her bilgi ve her araştırma uyuşturucuyla mücadele açısından çok önemlidir. Denetimli serbestlik biriminden hastanemize gönderilen olguların 2012 yılında \%26'sının, 2013'de \%46.5'nin 2014'de ise \%47.8'nin madde kullanıyor olması çok önemli bir sorunla karşı karşıya olduğumuzu göstermektedir. Antalya ilinde madde kullanımı, 2012 yıllna göre; 2013 yılında \% 82, 2014 yilında ise $\% 76$ oranında artmıştır. Madde kullanım oranı diğer illere kıyasla daha yüksek bulunmuştur. En sık kullanılan madde esrardır. Kadınların madde kullanım sıklığı artmıştır. Madde kullanım yaş ortalaması düşmüştür. Madde kullanan kişilerin \% 14’ü tedavi olmak istemiştir.

Madde bağımlılığı ile etkin mücadelede, kullanıcıların bireysel özelliklerinin, kültürel ve bireysel risk faktörlerinin 
anlaşılması önemlidir. Bu açıdan çalışmamız literatüre katkıda bulunacaktır. Bu çalışma, uyuşturucu madde kullanımı nedeniyle Antalya ilinde denetimli serbestlik uygulanan bireylerin özelliklerini ve tedavi sonuçlarını değerlendiren ilk çalışmadır. Ülkemizde 2006 yılında uygulamaya başlanan, madde bağımlılığının tedavisi için önemli olanaklar sunan denetimli serbestlik uygulamaları; madde kullanımındaki artışa paralel olarak daha da önem kazanacak ve başvuru sayısı artacaktır. Çalışmamız denetimli serbestlik merkezlerine bilgi kazandıracak ve bu tür çalışmalarla coğrafik, sosyoekonomik veriler doğrultusunda bireyin sorununu tanıyıp tedaviye istekli olmasını sağlayabilecek yöntemler geliştirilebilmesi, gençlerin eğitimi, işsizlikle mücadele, aile terapisi gibi uygulamalara önem verilmesiyle, tedavi başarısına önemli katkılar sağlayacaktır.

\section{Kaynaklar}

1. Özmen F, Kubanç Y. Liselerde madde bağımlılı̆̆1 - mevcut durum ve önerilere ilişkin okul müdürleri ve öğretmenlerin bakış açıları. International Periodical For The Languages, Literature and History of Turkish or Turkic 2013;8(3):357-382.

2. Türkiye uyuşturucu ve uyuşturucu izleme merkezi (TUBİM) 2013 ulusal raporu. http://www.kom.pol.tr/tubim Erişim Tarihi: 11.01.2015

3. Türkiye uyuşturucu ve uyuşturucu izleme merkezi (TUBİM) 2012 ulusal raporu. http://www.sck.gov.tr Erişim Tarihi:11.01.2015

4. Chari K, Baker JR, Lattirnore PK. A decision support system for partial drug testing: DSS-DT. Decision Support system 1998;23(3):241-57.

5. Belenko S. The impact of drug offenders on the criminal justice system. Drugs, crime and criminal justice system, Weigheit R(Ed), Anderson Publishing Co., Cincinnati, OH, 1990:27-78

6. Bahçeci B, H.Çelik F, Kandemir G, Güveli H, Polat S, Hocaoğlu Ç. Doğu Karadeniz bölgesinde bir eğitim ve araştırma hastanesine denetimli serbestlik kapsamında başvuran hastaların değerlendirilmesi: Bir yıllık geriye dönük çalışma. Adli Tıp Dergisi 2014;28(1):1-9.
7. Altıntoprak A.E, Akgür A.S, Kitapçığlu G, Yüncü Z, Coşkunol H. Denetimli serbestlik olgularının retrospektif analizi: Sosyodemografik özellikler, bireysel ve ailesel bağımlılık ve suç öyküleri ile tedavi yanıtları. Journal of Dependence. 2014;15(1):1-9.

8. United Nations Office on Drugs and Crime (UNODC). World Drug Report launched by UNODC in Stockholm, 2005;1-13.

9. Weich L, Pienaar W. Occurrence of comorbid substance use disorders among acute psychiatric inpatients at Stikland Hospital in the Western Cape, South Africa. Afr J Psychiatry (Johannesbg) 2009;12(3):213-7.

10. Bonsack C, Camus D, Kaufmann N, Aubert AC, Besson J, Baumann $\mathrm{P}$, at al. Prevalence of substance use in a Swiss psychiatric hospital: interview reports and urine screening. Addict Behav 2006;31(7):1252-8.

11. Doğanavşargil GÖ, Sertöz ÖÖ, Coşkunol H, Şen G. EÜTF Psikiyatri Anabilim Dalı Bağımlılık Tedavi Birimi'nin hasta verilerinin on yıllık geriye dönük olarak incelenmesi: Madde kullanan hastaların sosyodemografik özellikleri. Bağımlılık Dergisi 2004;5:115-20.

12. Subramanian GA, Stitzer MA. Clinical characteristics of treatmentseeking prescription opioids vs. heroin-using adolescents with opioid use disorder. Drug and Alcohol Dependence 2008;99 (3):141-149.

13. Evens E, Li L, Hser Y. Treatment entry barriers among California's proposition 36 offenders. Journal of Substance Abuse Treatment 2008;(35):410-418.

14. Gürol DT. Türkiye'de madde kullanımı ve tedavi politikaları. Türk Psikiyatri Derneği Bülteni 2009;12:47-8.

15. Karadeniz H, Birincioğlu İ, Seçilmifloğlu B, Savaş H, Zazoğlu S. Trabzon'da Denetimli Serbestlik Ve Yardım Merkezi Şube Müdürlüğü'nde madde bağımlılığ 1 nedeniyle kayıtlı olgularda toksikolojik analiz bulguları ve tedavi uygulamalarının değerlendirilmesi. Adli Tıp Bülteni 2009;14(2):80-87.

16. Zorlu N, Türk H, Manavgat Aİ, Karadaş B, Gülseren Ş. Denetimli serbestlik uygulaması kapsamında başvuran hastalarda sosyodemografik, klinik özelliklerin ve alkol kullanım bozukluğu sıklı̆̆ının geriye dönük değerlendirilmesi. Anadolu Psikiyatri Dergisi 2011;12(4):253-7. 